\title{
TOTAL KNEE ARTHROPLASTY; \\ EVALUATION OF THE PATIENT SATISFACTION, ITS COMPARISON WITH TRADITIONAL PHYSICIAN BASED SCORES, AT KARACHI, PAKISTAN.
}

1. MBBS, FCPS Part II Trainee, Post Graduate FCPS Part II Trainee Department of Orthopedics, Abbasi Shaheed Hospital, Karachi. 2. MBBS, FRCS

Professor and Head of Department of Orthopedic,

Abbasi Shaheed Hospital, Karachi.

3. MBBS, FCPS PART II Trainee Post Graduate FCPS Part II Trainee, Department of Neurosurgery, Abbasi Shaheed Hospital, Karachi.

\section{Correspondence Address:}

Dr Faisal Abdul Jabbar,

Address: B-69, Block-3,

Gulshan-e-lqbal,

Karachi-75300, Pakistan

drfaisaljabbar1@gmail.com

Article received on:

$14 / 04 / 2017$

Accepted for publication:

$15 / 06 / 2017$

Received after proof reading: 08/09/2017
Faisal Abdul Jabbar, Rehana Ali Shah², Muhammad Hashim ${ }^{3}$

ABSTRACT... Objectives: We aim to evaluate the level of satisfaction after total knee arthroplasty procedure in the patient population at a tertiary care hospital in Karachi, Pakistan, and to assess the relationship between patient satisfaction and the outcome based on traditional scores. Methods: Study Design: Case series for determination of patient satisfaction. Period: One year duration from April 2015 to May 2016. Setting: Tertiary care centre in Karachi, Pakistan. The inclusion criteria was all the patients with late stage osteoarthritis of the knee joint and underwent total knee arthroplasty at our institute. Data was analyzed using SPSS version 22. Results: A total of $n=102$ patients were included in the study while $n=109$ knee surgeries were done in total $(n=95$ patients had unilateral surgery, while $n=7$ patients had bilateral surgeries on both the knee joints) $n=58$ patients were females while $n=44$ patients were males, the median age was 60 years, patients had a mean body mass index (BMI) of $27 \mathrm{~kg} /$ $\mathrm{m}^{2}$. Of the total surgeries performed $n=100$ were in the satisfaction group while $n=9$ were in the dissatisfaction group. The majority of the patients reported that they would recommend the procedure. The co morbid conditions did not affect the patient's level of satisfaction having a $\mathrm{p}$ value of 0.678 . In the dissatisfied group, there was no significant difference when it comes to gender, the mean age of patients in the dissatisfaction group was higher than the mean age of patients in the satisfaction. We found that WOMAC scores for functioning and the final WOMAC scores were correlated with patient satisfaction and that was statistically significant, similarly SF-36 form patients were satisfied about the improvement in the physical health while they did not improve the mental health aspect of their disease. Conclusion: According to our study total knee arthroplasty is an effective treatment for osteoarthritis of the knee, patient satisfaction is correlated with post-operative WOMAC function and overall scores, and SF-36 physical component. It is important to keep patients expectations in check through proper counseling.

Key words: Osteoarthritis; patient satisfaction; total knee arthroplasty; TKA.

Article Citation: Jabbar FA, Shah RA, Hashim M. Total knee arthroplasty; Evaluation of the patient satisfaction, its comparison with traditional physician based scores, at Karachi, Pakistan. Professional Med J 2017;24(9):1403-1408.

DOI: $10.17957 / T P M J / 17.3979$

\section{INTRODUCTION}

About $10 \%$ of population above the age of 55 years suffer from osteoarthritis, which can be debilitating due to decreased range of motion and increased pain. ${ }^{1}$ Joint replacement is the last stage treatment ${ }^{2}$ for osteoarthritis that is effective, and total knee arthroplasty (TKA) is shown to decrease pain and increase the patient's range of motion. ${ }^{3,4,5}$ With the advancing science of orthopedic surgery many improvements have been made to the TKA procedure so as to improve the functional outcome, reduce complications and improve the patients quality of life. ${ }^{5}$ Outcomes after TKA procedure are assessed using the Knee society score (KSS) and the western Ontario and Mcmaster universities osteoarthritis index (WOMAC), which assess the pain and mobility of the knee joint. However some surgeons believe that patients own reported outcomes are to be involved in addition to these scores. ${ }^{6}$ Various factors influence the patient's level of satisfaction such as postoperative functionality, residual pain and postoperative complications. ${ }^{4,7,8,9,10}$ While studies report a dissatisfaction rate of $19 \%{ }^{15}$ Also patients prior expectations are also to be taken into account.8,11,12,13 Much of the work on patient satisfaction levels after TKA procedure has been done in the western countries as such not much 
work has been done from this region of the world, hence we aim to evaluate the level of satisfaction after total knee arthroplasty procedure in the patient population at a tertiary care hospital in Karachi, Pakistan, and to assess the relationship between patient satisfaction and the outcome based on traditional scores.

\section{MATERIALS AND METHODS}

The type of study is a case series for determination of patient satisfaction, conducted for a period of one year duration from April 2015 to May 2016, at a tertiary care centre in Karachi, Pakistan. The inclusion criteria was all the patients who signed a duly informed consent and agreed to participate in the study, who presented to us via the outpatient clinic with late stage osteoarthritis of the knee joint and underwent total knee arthroplasty at our institute. All the patients who refused to participate had rheumatoid arthritis, gout, inflammatory or post traumatic osteoarthritis. All the patients were followed for a period of one year duration. All the patients received thromboembolic prophylaxis via the use of thromboembolic deterrent stockings (TED stockings), early mobilization via physiotherapy on first post-operative day and encouragement of ambulation by third post-operative day. All the data collected from the patients that is, history, clinical examination, demographic data, pre and post-operative functional status of the joint, level of pain (using the visual analog system, from 1 to 10 , 1 being no pain and 10 being most extreme pain), post-operative complications were noted in a predesigned proforma. The patients satisfaction was recorded using various parameters (pain level, mobility, quality of life) and giving them a five point scale from most dissatisfied to most satisfied with neutral in between. Various standardized instruments such as KSS (knee function, pain, stability and range of motion), WOMAC (pain, stiffness, functional limitation) and Short Form 36 (SF-36) were also used to determine the symptoms and functional status of the patient both pre operatively and post operatively. These scoring systems were also administered after one year duration post operatively.

The patient's satisfaction levels were then compared to these standardized scoring systems. Patients were divided into two groups (those who responded to being satisfied either extremely satisfied or just satisfied, and the other group being those who were dissatisfied with the outcome) Patient satisfaction was also asked after one year post-operative period. Data was analyzed using SPSS version 22 and presented as mean and standard deviations, also as frequencies and percentages where applicable. Chi square test and fishers exact test were used to analyze the categorical variables, and student $t$ test was used to analyze continuous variables. A $p$ value of less than 0.05 was considered to be statistically significant.

\section{RESULTS}

A total of $n=102$ patients were included in the study while $n=109$ knee surgeries were done in total $(n=95$ patients had unilateral surgery, while $n=7$ patients had bilateral surgeries on both the knee joints) $n=58$ patients were females while $\mathrm{n}=44$ patients were males, the median age was 60 years with a range between 45 and 80 years of age, patients had a mean body mass index (BMI) of $27 \mathrm{~kg} / \mathrm{m}^{2}$, the other morbidities of the patients are listed in Table-I. Of the total surgeries performed $n=100$ were in the satisfaction group while $n=4$ were in the dissatisfaction group. The majority of the patients reported that they would recommend the procedure, the levels of satisfactions as per surgeries are listed in Table-l. The co morbid conditions did not affect the patient's level of satisfaction having a $p$ value of 0.678. $n=9$ patients were reported to either be neutral dissatisfied with the procedure. Of them there was no significant difference when it comes to gender having a $p$ value of 0.296 ( $n=5$ were male and $n=4$ were females), the mean age of patients in the dissatisfaction group was higher than the mean age of patients in the satisfaction group being 62.8 years versus 58.8 years. The mean BMl were similar in both the groups (27.2 versus $27.4 \mathrm{~kg} / \mathrm{m}^{2}$ ) these differences in the age and BMI were not statistically significant having $p$ values of 0.332 and 0.984 respectively. When it comes to the analysis of the standardized scores, we found that WOMAC scores for functioning and the final WOMAC scores were of satisfaction and 
that was statistically significant, while statistically insignificant scores were found for post-operative pain and stiffness of the joint scores. When it comes to the SF-36 form patients were satisfied about the improvement in the physical health while they did not improve the mental health aspect of their disease. The various components and its correlation with patient satisfaction is shown in Table-II. Pre-operative expectations were found to be statistically significant in predicting patient satisfaction having a $p$ value of 0.033 . Patients who had complications of proximal deep vein thrombosis and pulmonary embolism received anticoagulation therapy with low molecular weight heparin and warfarin. Among those who had distal deep venous thrombosis, three received anticoagulation therapy, one had myocardial infarction, and one had a superficial wound infection which was treated with antibiotics. These complications were not related to the patient's level of dissatisfaction having a $p$ value of 0.174 , however patients report these complication as source of dissatisfaction.

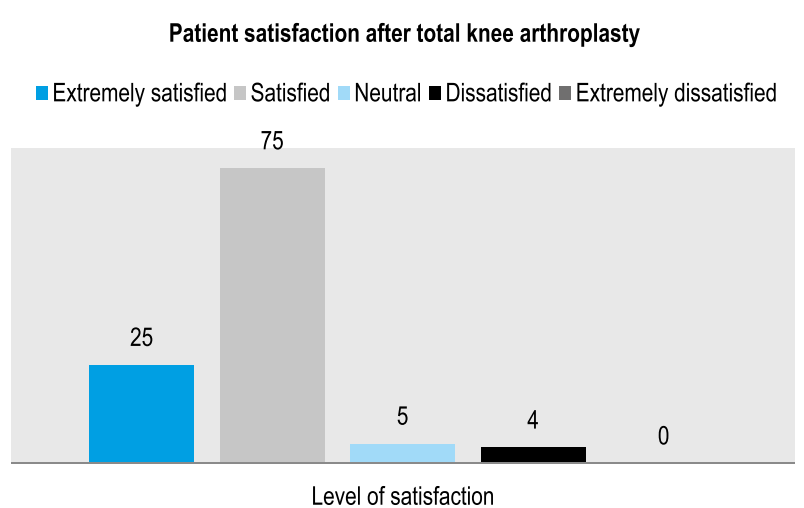

Figure-1. Patient satisfaction after total knee arthroplasty.

\section{DISCUSSION}

Osteoarthritis is fairly wide spread disease and is debilitating and affects the patients quality of life as it causes significant amounts of pain and loss of function of the knee joint. ${ }^{1,14}$ Although other modes of treatment such as conservative and surgical treatment exists the definitive therapy is joint replacement, and TKA has been shown to be an effective treatment option. ${ }^{2,4,15}$ But some studies report low levels of satisfaction with TKA $^{4,7,8,9,15,16}$

\begin{tabular}{|c|c|c|}
\hline Patient characteristics & $\begin{array}{c}\text { Number of } \\
\text { patients, } \\
n=102\end{array}$ & Percentage \\
\hline \multicolumn{3}{|l|}{ Patient expectations } \\
\hline Less pain & 55 & $53.92 \%$ \\
\hline Improved mobility & 49 & $48.03 \%$ \\
\hline $\begin{array}{l}\text { Improvement in overall } \\
\text { quality of life }\end{array}$ & 32 & $31.37 \%$ \\
\hline \multicolumn{3}{|l|}{$\begin{array}{l}\text { Post-operative } \\
\text { complications }\end{array}$} \\
\hline $\begin{array}{l}\text { Distal deep vein } \\
\text { thrombosis }\end{array}$ & 5 & $4.90 \%$ \\
\hline $\begin{array}{l}\text { Proximal deep vein } \\
\text { thrombosis }\end{array}$ & 3 & $2.94 \%$ \\
\hline $\begin{array}{l}\text { Bilateral pulmonary } \\
\text { embolism }\end{array}$ & 1 & $0.98 \%$ \\
\hline \multicolumn{3}{|l|}{ Co morbid conditions } \\
\hline Diabetes mellitus & 39 & $38.23 \%$ \\
\hline Hypertension & 80 & $78.43 \%$ \\
\hline Ischemic heart disease & 9 & $8.82 \%$ \\
\hline Stroke & 5 & $4.90 \%$ \\
\hline Prostate cancer & 2 & $1.96 \%$ \\
\hline $\begin{array}{l}\text { Chronic obstructive } \\
\text { pulmonary disease/ } \\
\text { Asthma }\end{array}$ & 6 & $5.88 \%$ \\
\hline \multicolumn{3}{|l|}{ Level of satisfaction } \\
\hline Extremely satisfied & 25 & $22.93 \%$ \\
\hline Satisfied & 75 & $68.80 \%$ \\
\hline Neutral & 5 & $4.58 \%$ \\
\hline Dissatisfied & 4 & $3.66 \%$ \\
\hline Extremely dissatisfied & 0 & $0 \%$ \\
\hline
\end{tabular}

Hence many different scores and methods were developed to assess the outcome of this procedure, including the surgeons questioning the patient about his illness and treatment ${ }^{8}$ and objective scales such as WOMAC,KSS, SF-36 etc which have shown some degree of correlation with patient satisfaction ${ }^{17}$, but still some patients are dissatisfied, some studies report a dissatisfaction rate of $19 \%^{7,8,9,16}$

And it is also known that there is a dissonance between the surgeon reported outcomes and patient reported outcomes. In a study by Yuan et $\mathrm{al}$, it is reported that the outcome of 60 patients satisfaction to be $91 \%$ [9] while Nunez et al in a study of 112 patients report satisfaction rate to be $86 \%{ }^{16}$ Which are similar to our study results of $91.74 \%$. 


\begin{tabular}{|c|c|c|c|}
\hline \multirow[t]{2}{*}{ Scoring system used } & \multicolumn{2}{|c|}{ Score Mean and standard deviation } & \multirow[t]{2}{*}{$P$ value } \\
\hline & Satisfied group & Dissatisfied group & \\
\hline \multicolumn{4}{|l|}{ Pre-op WOMAC } \\
\hline Pain & $52.8+/-19.6$ & $45.1+/-16.9$ & 0.206 \\
\hline Stiffness & $62.2+/-28.1$ & $50.0+/-26.6$ & 0.187 \\
\hline Function & $47.4+/-18.5$ & $41.8+/-19.5$ & 0.467 \\
\hline Final score & $50.1+/-16.4$ & $46.9+/-14.9$ & 0.555 \\
\hline \multicolumn{4}{|l|}{ Post-op WOMAC } \\
\hline Pain & $96.8+/-6.2$ & $93.1+/-8.8$ & 0.136 \\
\hline Stiffness & $94.5+/-11.5$ & $91.7+/-10.9$ & 0.259 \\
\hline Function & $85.5+/-13.1$ & $74.5+/-18.0$ & 0.028 \\
\hline Final score & $87.7+/-7.9$ & $80.0+/-11.9$ & 0.040 \\
\hline \multicolumn{4}{|l|}{ Change in WOMAC } \\
\hline Pain & $44.2+/-20.4$ & $47.8+/-14.2$ & 0.450 \\
\hline Stiffness & $32.3+/-30.5$ & $41.7+/-27.2$ & 0.297 \\
\hline Function & $38.1+/-17.8$ & $33.0+/-16.3$ & 0.485 \\
\hline Final score & $37.5+/-16.4$ & $33.2+/-10.6$ & 0.674 \\
\hline \multicolumn{4}{|l|}{ Short Form-36 } \\
\hline Change in physical component score & $21.2+/-7.5$ & $14.2+/-4.8$ & 0.004 \\
\hline Change in mental component score & $11.8+/-52.6$ & $7.5+/-8.8$ & 0.840 \\
\hline \multicolumn{4}{|l|}{ Knee Society score } \\
\hline Change in function & $28.5+/-23.3$ & $21.8+/-19.9$ & 0.435 \\
\hline Change in knee & $69.3+/-83.5$ & $57.5+/-15.8$ & 0.434 \\
\hline
\end{tabular}

Preoperative expectations have been shown to have a positive correlation with post-operative levels of satisfaction ${ }^{8,11,12,13}$ Gandhi et al and Mahomed et al report the same. ${ }^{11,12}$ However in our study we did not find any such correlation. However we found that for those patients who preoperative expectations were fulfilled showed post-operative satisfaction, which is also in agreement to a study by Bourne et al. ${ }^{8}$ Many different factors affect the patients level of satisfaction, such as patients mental health status, pre-operative functioning and pain levels of the knee joint, postoperative functioning and pain levels, complications, revision surgery, gender, age and type of arthritis of the knee joint respectively. $4,7,8,9,10,12,18,19,20,21$ Some studies have reported a correlation between poor WOMAC scores and lower satisfaction levels of the patients..$^{19,20,21}$ but according to Lingard et al there was no significant difference in the WOMAC scores of satisfied and dissatisfied patients. ${ }^{18}$ We found similar results in our study, that preoperative WOMAC scores were not correlated with patient satisfaction having a p value of 0.555 , but good post-operative WOMAC functioning scores and overall scores along with good SF36 scores (physical component) had a positive correlation in predicting the levels of patient satisfaction. Complication rate of TKA is found to be $30 \%^{22}$ but Yuan et al reported a lower complication rate of $13.5 \%{ }^{9}$, which are similar to our rates of complications. They also correlated that the development of complications leads to a lower level of satisfaction for the patients. ${ }^{16}$ But we did not find such association $p$ value of 0.174 , also some studies suggest co morbid conditions to be the reason of poor outcome ${ }^{19,23}$ we failed to find such an association having a $p$ value of 0.678 . We had some limitations in our study such as a small sample size, also we did not analyze the effect of mental health of outcome of TKA, and also our follow up period was of one year duration only.

\section{CONCLUSION}

According to our study total knee arthroplasty is an effective treatment for osteoarthritis of the knee, patient satisfaction is correlated with postoperative WOMAC function and overall scores, and SF-36 physical component. It is important to keep patients expectations in check through 
proper counseling.

Copyright(c) 15 June, 2017.

\section{REFERENCES}

1. Felson DT. The epidemiology of knee osteoarthritis: results from the Framingham Osteoarthritis Study. Semin Arthritis Rheum 1990; 20(3 Suppl 1):42-50.

2. Fraenkel L, Bogardus ST Jr, Concato J, Wittink DR. Treatment options in knee osteoarthritis: the patient's perspective. Arch Intern Med 2004; 164:1299-304.

3. Riley LH Jr. Total knee arthroplasty. Clin Orthop Relat Res 1985; (192):34-9.

4. Genêt F, Schnitzler A, Lapeyre E, et al. [Change of impairment, disability and patient satisfaction after total knee arthroplasty in secondary care practice]. Ann Readapt Med Phys 2008; 51:671-6, 676-82. English, French.

5. Mainard D, Guillemin F, Cuny C, et al. [Quality of life assessment one year after total hip or knee arthroplasty]. Rev Chir Orthop Reparatrice Appar Mot 2000; 86:464-73. French.

6. Janse AJ, Gemke RJ, Uiterwaal CS, et al. Quality of life: patients and doctors don't always agree: a metaanalysis. J Clin Epidemiol 2004; 57:653-61.

7. Anderson JG, Wixson RL, Tsai D, Stulberg SD, Chang RW. Functional outcome and patient satisfaction in total knee patients over the age of 75 . J Arthroplasty 1996; 11:831-40.

8. Bourne RB, Chesworth BM, Davis AM, Mahomed NN, Charron KD. Patient satisfaction after total knee arthroplasty: who is satisfied and who is not? Clin Orthop Relat Res 2010; 468:57-63.

9. Yuan $A$, Cai $D$, Wang $K$. [Analysis of factors relating to clinical outcomes after total knee replacement]. Zhongguo Xiu Fu Chong Jian Wai Ke Za Zhi 2007; 21:235-9. Chinese.

10. Lonner JH, Lotke PA. Aseptic complications after total knee arthroplasty. J Am Acad Orthop Surg 1999; 7:311-24.

11. Mahomed NN, Liang $\mathrm{MH}$, Cook EF, et al. The importance of patient expectations in predicting functional outcomes after total joint arthroplasty. J Rheumatol 2002; 29:1273-9.

12. Gandhi R, Davey JR, Mahomed N. Patient expectations predict greater pain relief with joint arthroplasty. $\mathrm{J}$
Arthroplasty 2009; 24:716-21.

13. Noble PC, Conditt MA, Cook KF, Mathis KB. The John Insall Award: Patient expectations affect satisfaction with total knee arthroplasty. Clin Orthop Relat Res 2006; 452:35-43.

14. Nguyen US, Zhang $Y$, Zhu $Y$, et al. Increasing prevalence of knee pain and symptomatic knee osteoarthritis: survey and cohort data. Ann Intern Med 2011; 155:725-32.

15. Laskin RS. The classic: modular total kneereplacement arthroplasty. A review of eighty-nine patients. 1976. Clin Orthop Relat Res 2008; 466:2581-8.

16. Núñez M, Lozano $L$, Núñez $E$, et al. Total knee replacement and health-related quality of life: factors influencing long-term outcomes. Arthritis Rheum 2009; 61:1062-9.

17. Becker R, Döring C, Denecke A, Brosz M. Expectation, satisfaction and clinical outcome of patients after total knee arthroplasty. Knee Surg Sports Traumatol Arthrosc 2011; 19:1433-41.

18. Lingard EA, Riddle DL. Impact of psychological distress on pain and function following knee arthroplasty. J Bone Joint Surg Am 2007; 89:1161-9.

19. Lingard EA, Katz JN, Wright EA, Sledge CB; Kinemax Outcomes Group. Predicting the outcome of total knee arthroplasty. J Bone Joint Surg Am 2004; 86-A: 2179-86.

20. Lavernia C, D’Apuzzo M, Rossi MD, Lee D. Is postoperative function after hip or knee arthroplasty influenced by preoperative functional levels? J Arthroplasty 2009; 24:1033-43.

21. Kim TK, Kwon SK, Kang YG, Chang CB, Seong SC. Functional disabilities and satisfaction after total knee arthroplasty in female Asian patients. J Arthroplasty 2010; 25:458-464.e1-2.

22. Callahan CM, Drake BG, Heck DA, Dittus RS. Patient outcomes following unicompartmental or bicompartmental knee arthroplasty. A meta-analysis. J Arthroplasty 1995; 10:141-50.

23. Ghomrawi HM, Kane RL, Eberly LE, Bershadsky B, Saleh KJ; North american knee arthroplasty revision (NAKAR) Study Group. Patterns of functional improvement after revision knee arthroplasty. J Bone Joint Surg Am 2009; 91:2838-45. 


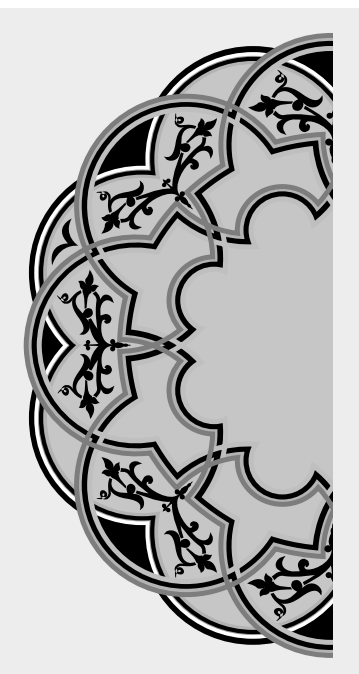

\title{
"Forgiveness is the best revenge."
}

\author{
Unknown
}

\begin{tabular}{|c|c|c|c|}
\hline \multicolumn{3}{|c}{ AUTHORSHIP AND CONTRIBUTION DECLARATION } \\
\hline Sr. \# & Author-s Full Name & \multicolumn{1}{|c|}{ Contribution to the paper } \\
\hline 1 & Faisal Abdul Jabbar & $\begin{array}{l}\text { Corresponding author, Write up, } \\
\text { Data collection, Data analysis, } \\
\text { Literature review. } \\
\text { Write up, Data collection, Definition } \\
\text { of intellectual content, Literature } \\
\text { review final draft, Proof reading. } \\
\text { Write up, Data analysis, Literature } \\
\text { review }\end{array}$ \\
\hline 3 & Muhammad Hashimatim & Rehana Ali Shah \\
\hline
\end{tabular}

